Schattenberg - Stalins Ingenieure 


\title{
Ordnungssysteme
}

\author{
Studien
}

zur Ideengeschichte der Neuzeit

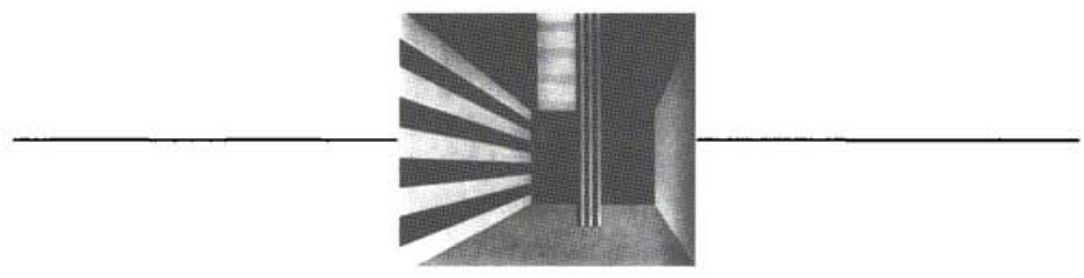

Herausgegeben von

Dietrich Beyrau, Anselm Doering-Manteuffel

und Lutz Raphael

Band 11

R. Oldenbourg Verlag München 2002 


\section{Susanne Schattenberg}

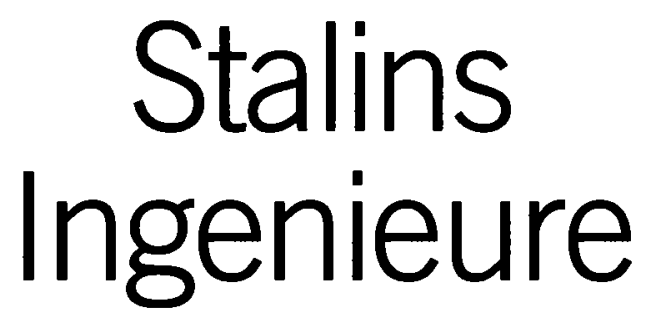

Lebenswelten

zwischen Technik und Terror

in den 1930er Jahren

R. Oldenbourg Verlag München 2002 
Gedruckt mit Unterstützung der Deutschen Forschungsgemeinschaft

Die Deutsche Bibliothek - CIP Einheitsaufnahme

Schattenberg, Susanne:

Stalins Ingenieure : Lebenswelten zwischen Technik und Terror in den 1930er Jahren / Susanne Schattenberg. - München : Oldenbourg, 2002

(Ordnungssysteme ; Bd. 11)

Zugl.: Frankfurt (Oder), Europa-Univ., Diss., 1999

ISBN 3-486-56678-4

(1) 2002 Oldenbourg Wissenschaftsverlag GmbH, München Rosenheimer Straße 145, D-81671 München

Internet: http://www.oldenbourg-verlag.de

Das Werk einschließlich aller Abbildungen ist urheberrechtlich geschützt. Jede Verwertung außerhalb der Grenzen des Urheberrechtsgesetzes ist ohne Zustimmung des Verlages unzulässig und strafbar. Dies gilt insbesondere für Vervielfältigungen, Übersetzungen, Mikroverfilmungen und die Einspeicherung und Bearbeitung in elektronischen Systemen.

Umschlaggestaltung: Dieter Vollendorf

Gedruckt auf säurefreiem, alterungsbeständigem Papier (chlorfrei gebleicht).

Gesamtherstellung: Druckhaus „Thomas Müntzer“ GmbH., Bad Langensalza

ISBN 3-486-566678-4 